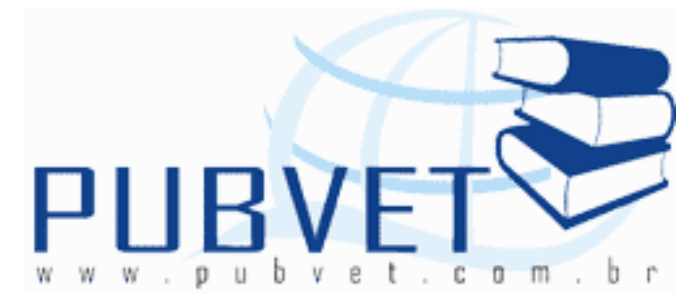

PUBVET, Publicações em Medicina Veterinária e Zootecnia.

\title{
Estudo morfológico comparado do trato gastrointestinal de gruiformes
}

\author{
André Luiz Quagliatto Santos ${ }^{1}$, Mariana Batista Andrade ${ }^{3}$, Rogério Rodrigues de \\ Souza², Lorena Tannús Menezes², Caio Henrique Ferreira² ${ }^{2}$, Sérgio Rodrigo \\ Pereira de Oliveira ${ }^{2}$, Árthur Paulino Sanzo Kaminishi ${ }^{2}$, Liliane Rangel \\ Nascimento ${ }^{2}$, Flávio Machado de Moraes ${ }^{1}$
}

Laboratório de Ensino e Pesquisa em Animais Silvestres - LAPAS, FAMEV/UFU, e-mail: quagliatto@famev.ufu.br 1. Docente. 2. Mestrandos. 3. Doutoranda.

\section{Resumo}

O Brasil apresenta uma das maiores riquezas em avifauna do mundo com mais de 1700 espécies, das quais mais de $10 \%$ é endêmico, o que torna o país um dos mais importantes em relação a investimentos em conservação. Fato que desperta a necessidade por maiores conhecimentos de ordem anatômica e fisiológica nestes animais. O aparelho digestório é o "compartimento" do organismo responsável pela manutenção da vida, sendo o tubo digestório de cada ave adaptado para processar e utilizar o mais eficientemente possível o alimento disponível em seu habitat. Com o intuito de se ampliar os conhecimentos anatômicos gastrointestinal das aves, abordaram-se em um estudo comparativo, utilizando cinco exemplares de aves, representantes da ordem Gruiformes, doadas pelo IBAMA-Uberlândia/MGE enviadas ao Laboratório de Ensino e Pesquisa em Animais Silvestres (LAPAS) da UFU onde os animais foram fotografados, identificadas quanto à ordem, gênero e espécie 
e dissecadas, com a finalidade de se obter informações relativas à topografia, forma e dimensões dos segmentos do tubo digestório nas diferentes espécies. Ao final da pesquisa foram observadas algumas diferenças relativas à topografia, dimensões e composição do tubo digestório, entre as espécies da mesma ordem. Características observadas de maior relevância incluem o formato fusiforme característico no estomago químico do frango-d' água-azul, quando comparado com as outras espécies.

Palavras-chave: aves, anatomia comparada, estomago.

\section{Morphological comparative gastrointestimal tract of birds of Gruiforms}

\section{Summary}

Brazil has a greater wealth of birdlife in the world with over 1700 species, of which more than $10 \%$ are endemic, which makes the country one of the most important in relation to investments in conservation. Fact that arouses the need for more knowledge of anatomical and physiological order in these animals. The digestive system is the "box" of the body responsible for the maintenance of life, and the digestive tract of each bird adapted to process and use as efficiently as possible the food available in their habitat. In order to increase their knowledge of poultry anatomical gastrointestinal, approached in a comparative study using five specimens of birds, representing the Gruiform order, donated by IBAMA, Uberlândia/MG and were send to the Laboratory Teaching and Research in Wildlife (LAPAS) UFU_of the animals were photographed, identified as to the order, genus, species and dissected for the purpose of obtaining information on topography, shape and dimensions of the segments of the digestive tract in different species. At the end of the study were observed some differences in the topography, size and composition of the digestive tract, between species of the same order. Features seen include the most relevant characteristic spindle form in the stomach chemical common moorhen blue, when compared with other species.

Keywords: birds, comparative anatomy, stomach. 
SANTOS, A.L.Q. et al. Estudo morfológico comparado do trato gastrointestinal de gruiformes.

PUBVET, Londrina, V. 6, N. 13, Ed. 200, Art. 1342, 2012.

\section{Introdução}

O Brasil reúne uma das maiores riquezas em avifauna do mundo com mais de 1700 espécies, das quais mais de $10 \%$ é endêmico, o que torna o país um dos mais importantes em relação a investimentos em conservação. Por outro lado, o país sofre forte pressão do tráfico de animais silvestres (RENCTAS, 2002).

O sistema digestivo das aves, à semelhança do que ocorre com o sistema termorregulador e o imunológico, sofre um processo de maturação no período pós-eclosão o que implica em um melhor funcionamento com o desenvolvimento da ave (PELICANO et al., 2003). Macari et al. (1994) observaram que o número de vilosidades e o tamanho destas, bem como o de microvilos, em cada segmento do intestino delgado, conferem a este características próprias, sendo que na presença de nutrientes a capacidade absortiva do segmento será diretamente proporcional ao número de vilosidades ali presentes, tamanho das vilosidades e área de superfície disponível para a absorção.

O sistema digestório é responsável pela absorção de nutrientes a partir dos compostos químicos absorvidos pelo organismo para manutenção e produção animal (FRANZO et al., 2008).

Este é um tubo oco revestido de fibra muscular, que vai da boca á cloaca, recoberto por um epitélio que, em algumas partes, é especializado para secreção, digestão e absorção (MENDES e GONZALES, 1994).

Os patógenos representam também um grande problema para o desenvolvimento de qualquer espécie animal. Ambientes livres de patógenos ocasionam redução na altura das vilosidades, bem como na profundidade de cripta, sugerindo que o crescimento normal do epitélio intestinal depende também do equilíbrio da microbiota ali residente (COOK e BIRD, 1973).

O esôfago é dividido anatomicamente em porção cervical, parte mais longa que segue dorsalmente à traqueia e retorna à linha média na porção imediatamente cranial à entrada torácica (MCLELLAND, 1986) e porção 
SANTOS, A.L.Q. et al. Estudo morfológico comparado do trato gastrointestinal de gruiformes.

PUBVET, Londrina, V. 6, N. 13, Ed. 200, Art. 1342, 2012.

torácica, que passa sobre a bifurcação da traqueia e a base do coração e funde-se com o estômago glandular à esquerda do plano mediano (DYCE, SACK e WENSING, 1997).

O estômago é dividido por uma constrição em proventrículo (parte glandular) e ventrículo ou moela (parte muscular), situados um atrás do outro no plano mediano (DYCE, SACK e WENSING, 1997).

O intestino delgado possui a mucosa repleta de vilosidades altas e delgadas (DUKES, 1996), onde ocorre a principal fase da digestão química (POUGH, HEISER e MCFARLAND, 1999).

O intestino grosso consiste de um par de cecos, e um intestino curto e reto, contínuo com íleo e cloaca para o qual não há terminologia aceita (MCLELLAND, 1986).

Os cecos possuem a parede mais fina que os demais segmentos do trato intestinal (MCLELLAND, 1986) originam-se na junção ileocólica e acompanham o íleo, ao qual se ligam por pregas ileocecais (DYCE, SACK e WENSING, 1997).

O reto é um segmento curto, que se entende como um tubo quase reto do íleo até a cloaca (MCLELLAND, 1986) cujo papel essencial é acumular fezes (SCHWARZE, 1980). Propôs-se realizar uma descrição anatômica comparativa do tubo digestório dos Gruiformes, sendo Porphyrula Martinica (frango-d' água-azul), Cariamacristata (seriema), Aramidescajanea (saracura-três-potes), Aramidesypecaha (saracuraçu), enfocando as principais características topográficas e particularidades anatômicas dos representantes.

\section{MATERIAL E MÉTODOS}

Este estudo foi realizado utilizando-se cinco aves de diferentes espécies da ordem Gruiformes sendo dois exemplares Porphyrula Martinica (frango-d' água-azul), uma Cariamacristata (seriema), uma Aramidescajanea (saracuratrês-potes), uma Aramidesypecaha (saracuraçu), doados pelo IBAMA Uberlândia-MG e enviados ao Laboratório de Ensino e Pesquisa em Animais Silvestres (LAPAS) da Faculdade de Medicina Veterinária da Universidade 
SANTOS, A.L.Q. et al. Estudo morfológico comparado do trato gastrointestinal de gruiformes.

PUBVET, Londrina, V. 6, N. 13, Ed. 200, Art. 1342, 2012.

Federal de Uberlândia, onde foram fotografados, de modo a enfatizar aspectos individuais que diferenciam as espécies.

A identificação das aves incluiu sua classificação quanto à ordem, gênero e espécie e foram realizadas com auxílio da Lista das aves do Brasil (2011), Souza (1998), Juniper e Pan (1998).

Quadro 1: Identificação dos exemplares de estudo quanto à ordem, espécie, nome popular, número de registro, sexo, comprimento total da ave e quantidade total do representante, nesta ordem.

\begin{tabular}{|l|l|l|l|l|l|l|}
\hline Ordem & Espécie & Nome popular & n.r & sexo & c.t (cm) & no.ex \\
\hline \multirow{3}{*}{ Gruiformes } & PorphyrulaMartinica & frango-d'água-azul & 4 & F & 28,60 & 02 \\
& & & 4.1 & M & 30,00 & \\
\cline { 2 - 8 } & Cariamacristata & seriema & 2 & M & 80,42 & 01 \\
\cline { 2 - 8 } & Aramidescajanea & saracura-três- & 1 & F & 27,50 & 01 \\
\cline { 2 - 8 } & Aramidesypecaha & Saracuraçu & 3 & F & 44,30 & 01 \\
\hline
\end{tabular}

c.t - comprimento total da ave (cm); n.r - número de registro da ave; $\mathrm{n}^{0}$. ex número de exemplares da espécie; F - fêmea; M - Macho; _ - sexo não identificável

Cada exemplar, depois de submetido ao processo completo de dissecação e registro das informações relevantes, foi conservado em solução de formaldeído a $10 \%$ injetada em toda a musculatura das aves com seringas descartáveis de 1,5 ou $10 \mathrm{ml}$ e agulha hipodérmica $30-8$ ou agulha descartável de $13 \times 0,45 \mathrm{~mm}$ dependendo do tamanho da ave em questão. Cada ave foi dissecada a fresco, com a finalidade de manter os órgãos em suas dimensões originais, obtendo-se medidas de comprimento e diâmetro com mínima margem de erro. Concomitantemente, procedeu-se à descrição e elaboração de desenhos esquemáticos (figura 3 e 4 ) e fotografias (figuras 1 e 2) 
SANTOS, A.L.Q. et al. Estudo morfológico comparado do trato gastrointestinal de gruiformes.

PUBVET, Londrina, V. 6, N. 13, Ed. 200, Art. 1342, 2012.

enfocando características relativas a dimensionamento, topografia, morfologia e composição do tubo digestivo.

O comprimento total de cada ave, que consiste na distância entre a extremidade rostral do bico até a extremidade caudal da última pena da cauda, foi obtido com o animal em decúbito dorsal e com o pescoço estendido.

Com o auxílio de um cabo de bisturi no 4, uma lâmina para bisturi no 23, uma pinça Adson e uma pinça anatômica procederam-se a abertura da cavidade toracoabdominal de cada exemplar a partir de uma incisão na linha mediana ventral (delimitada pelo osso esterno e cloaca) e posterior retirada do plastrão (utilizando uma cisalha $19 \mathrm{~cm}$ simples, nas aves de maior porte).

Foram adotados os seguintes pontos de referência para descrição anatômica e mensuração dos segmentos do tubo digestivo:

- Esôfago cervical: início na laringe e término na entrada da cavidade tóracoabdominal;

- Inglúvio: início na região de dilatação do esôfago cervical e término na extremidade cranial do esôfago torácico;

- Esôfago torácico: início na entrada da cavidade e término na junção com o proventrículo;

- Proventrículo: início na união com esôfago torácico e término na divisão com o ventrículo ou no istmo, quando presente;

- Ventrículo: início na união com o proventrículo e término no início da alça descendente do duodeno;

- Alça descendente do duodeno: início no piloro e término na curvatura de união com a alça ascendente do duodeno;

- Alça ascendente do duodeno: início na união com a alça anterior e término na curvatura de união ao segmento jejunoilíaco;

- Jejuno-íleo: início na união com o segmento anterior e término na divisão com coloreto, considerando-se a presença de cecos, quando existirem;

- $\operatorname{Ceco(s):~do~seu~ponto~de~inserção~no~segmento~intestinal~ao~seu~ápice;~}$ 
- Coloreto: início na base do(s) ceco(s), quando existirem ou do momento em que se desfazem as alças que compõem o segmento jejunoilíaco e término na cloaca;

Após descrição topográfica, o tubo digestivo foi individualizado com o auxílio de uma pinça anatômica, uma pinça hemostática, uma pinça dente de rato, uma tesoura Mayo curva e uma tesoura Metzembaum reta, divulsionando-se os tecidos que mantinham os segmentos do tubo digestivo relacionado a outros órgãos.

Cada órgão foi mensurado com um paquímetro Starret de precisão 0,05 $\mathrm{mm}$, de modo a registrar o comprimento e diâmetro dos mesmos. As medidas de diâmetro tomadas não se apresentam de maneira constante para todas as aves, uma vez que variaram de acordo com o estado de distensão do órgão no momento do óbito da ave.

Estabeleceu-se uma relação, em porcentagem média, entre o comprimento de cada segmento do tubo digestivo e o comprimento total dos exemplares da ordem Gruiformes.

As informações referentes à descrição anatômica em cada ave foram anotadas em fichas individuais. (Quadro 2 a 6 )

\section{RESULTADOS}

Ordem Gruiforme

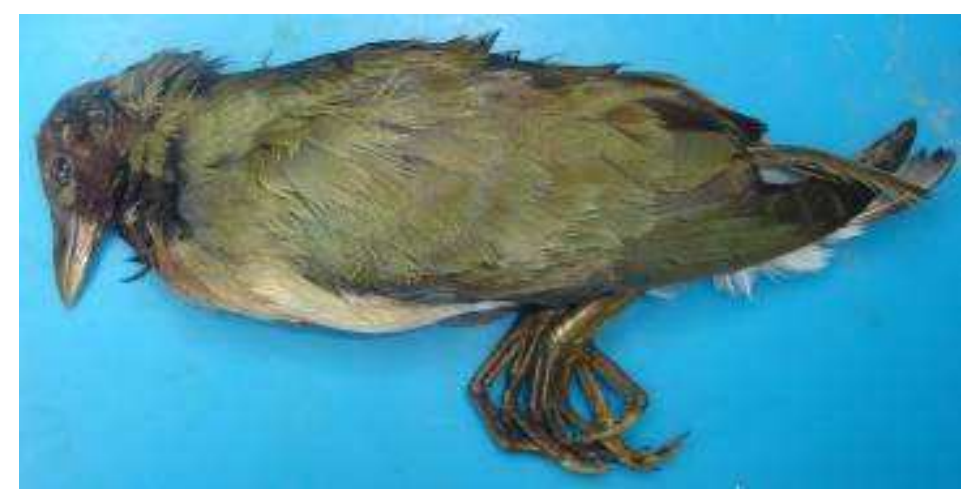

Figura 01: Saracura-três-potes Aramidescajanea

Statius Müller, 1776 (RALLIDAE). 


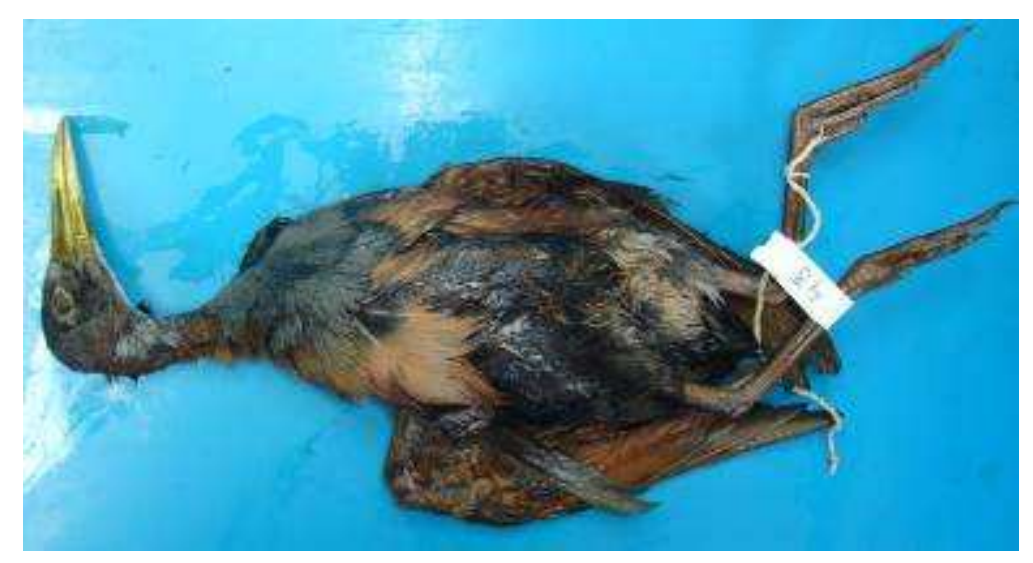

Figura 02: Saracuraçu Aramidesypecaha Vieillot, 1819 (RALLIDAE).

Além dos representantes ilustrados, estão incluídos nesta ordem:

- Frango-d' água-azul Porphyriomartinica Linnaeus, 1766 (RALLIDAE).

- Seriema Cariamacristata Linnaeus, 1766 (CARIAMIDAE).

Em saracura-três-potes o esôfago cervical inicia-se dorsalmente à traqueia, na face ventral do pescoço. No terço inicial do mesmo se desvia para direita, mantendo sua trajetória dorsolateralmente à traqueia até a entrada da cavidade toracoabdominal. Já em frango-d' água-azul a porção cervical se mantem dorsolateralmente a traqueia durante todo 0 seu percurso. Representa, em média $24,56 \%$ do comprimento total das aves.

Haja vista a ausência de inglúvio, o esôfago torácico é subsequente à porção cervical e tem início na entrada da cavidade tóracoabdominal segue dorsalmente à traqueia, siringe, bifurcação traqueal e ventralmente aos lobos pulmonares unindo-se ao proventrículo em nível da extremidade cranial do lobo hepático esquerdo. Equivale em média, a 11,90\% do comprimento total dos representantes.

O estômago químico possui formato fusiforme característico em frango-d' água-azul, e cilíndrico nos outros exemplares. Localiza-se em posição para mediana esquerda, dorsalmente a praticamente todo lobo hepático esquerdo, no qual deixa uma impressão hepática e ventralmente à metade caudal do lobo 
SANTOS, A.L.Q. et al. Estudo morfológico comparado do trato gastrointestinal de gruiformes.

PUBVET, Londrina, V. 6, N. 13, Ed. 200, Art. 1342, 2012.

pulmonar esquerdo e ovário (na fêmea) ou testículo esquerdo (no macho). Representa em média, $6,87 \%$ do comprimento total das aves.

O ventrículo dispõe-se obliquamente na cavidade, do antímero direito para o esquerdo e possui formato de lente biconvexa. A porção cranial de sua face ventral está relacionada ao terço caudal dos lobos hepáticos. Situam-se ventralmente as alças jejunoilíacas, cecos pares e pequena porção inicial do coloreto. Equivale em média, a 8,67\% do comprimento total das aves.

O duodeno tem início na região central da porção cranial da face dorsal da moela através da alça descendente do duodeno, que segue caudolateralmente contornando o ventrículo. Em saracura-três-potes a alça se projeta dorsalmente e faz uma curva ventralmente à porção final do coloreto. Em frango-d' água-azul, a curva que une a alça descendente à alça ascendente do duodeno localiza-se dorsalmente à borda caudal do ventrículo. Representa em média, $12,42 \%$ do comprimento total das aves.

A alça ascendente do duodeno faz a trajetória oposta, dorsolateralmente à porção descendente e une-se ao segmento jejuno-íleo através de uma curva dorsal, ventralmente aos cecos e caudalmente a vesícula biliar. Equivale em média, a 12,91\% do comprimento total dos representantes. Jejuno-íleo está disposto em alças frouxas, unidas por mesentério, situadas ventralmente aos rins e coloreto e dorsalmente aos cecos e moela. Representa em média, 70,49\% do comprimento total dos representantes.

A divisão entre o segmento jejuno-íleo e coloreto é feita por um par de cecos bem desenvolvidos, de formato tubular e metade distal dilatada, formando uma bolsa. Emergem à nível do lobo renal cranial esquerdo unemse às alças jejuno-íleo e coloreto por mesentério. Estão direcionados craniolateralmente, do lado esquerdo para o lado direito da cavidade, dorsalmente ao ventrículo e ventralmente aos lobos renais craniais e médios esquerdos. O ceco esquerdo é mais cranial que o direito e equivale em média a $12,70 \%$ do comprimento total dos representantes, enquanto que o direito equivale a $12,19 \%$. 
O coloreto segue em posição paramediana esquerda, ventralmente aos lobos renais médio e caudal, até a cloaca e representa em média, 11,40\% do comprimento total das aves.

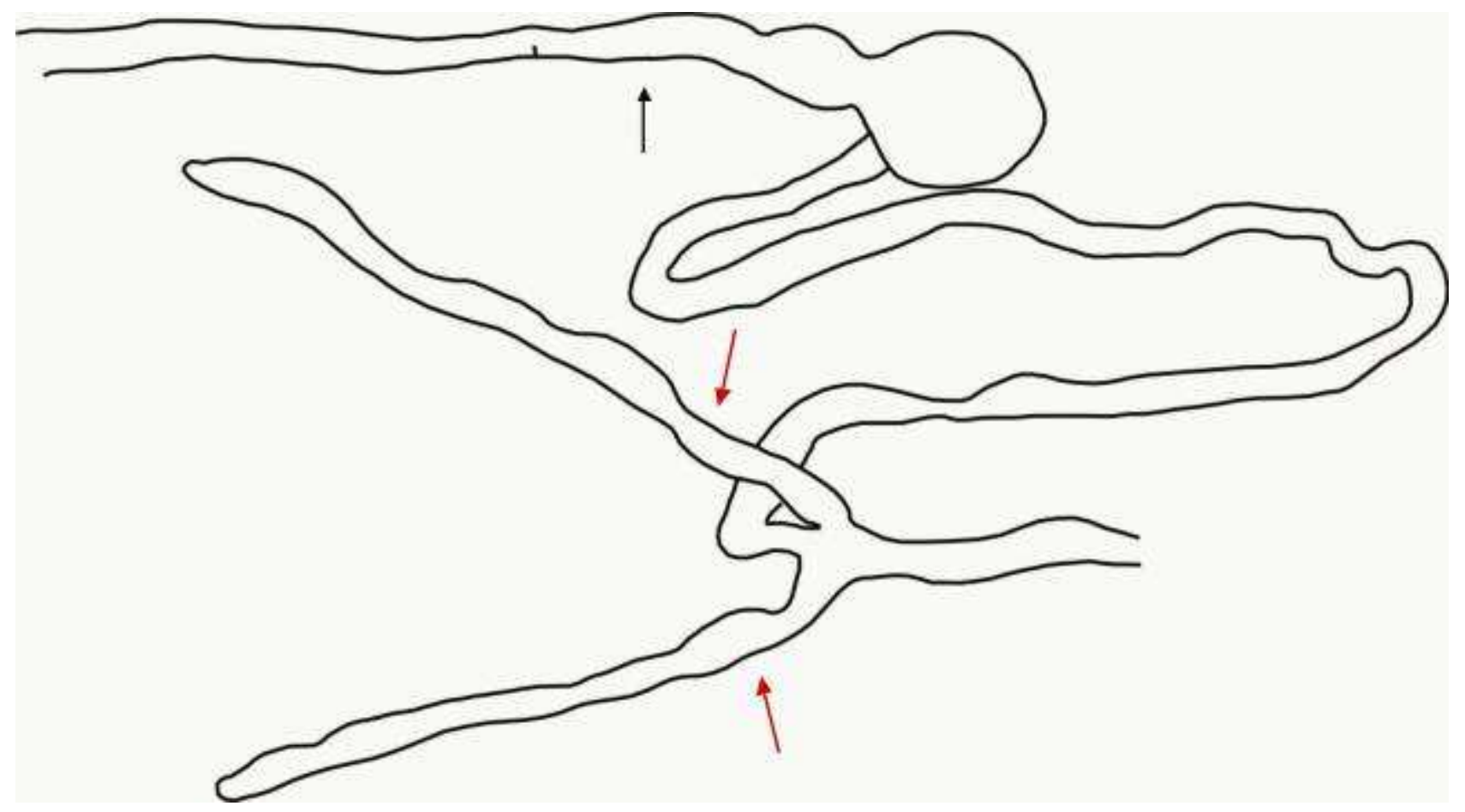

Figura 3: Tubo digestório de seriema. Transição entre esôfago cervical e esôfago torácico (seta preta); cecos direito e esquerdo (setas vermelhas).

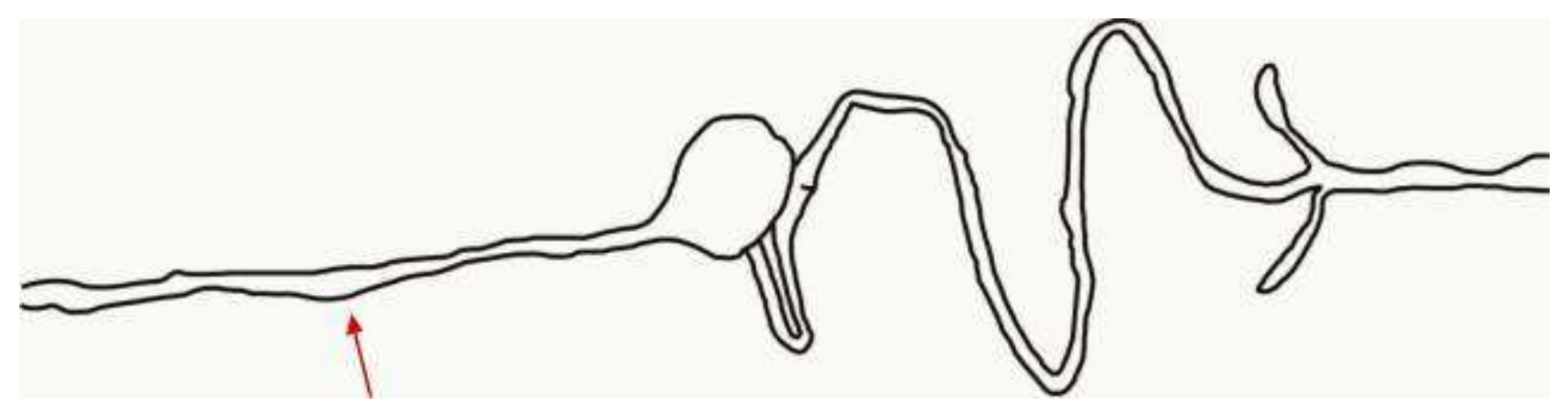

Figura 4: Tubo digestório de saracura-três-potes. Transição entre esôfago cervical e esôfago torácico (seta vermelha). 
Quadro 2: Comprimento e diâmetro dos componentes do tubo digestivo de um exemplar saracura-três-potes, no 1

\begin{tabular}{|l|c|c|}
\hline \multicolumn{1}{|c|}{ Órgão } & Comprimento (mm) & Diâmetro (mm) \\
\hline Esôfago cervical & 71,95 & 4,15 \\
\hline Esôfago torácico & 39,35 & 2,30 \\
\hline Proventrículo & 17,50 & 5,00 \\
\hline $\begin{array}{l}\text { Ventrículo * } \\
\text { Alça descendente do } \\
\text { duodeno }\end{array}$ & 34,50 & 2,90 \\
\hline $\begin{array}{l}\text { Alça ascendente do } \\
\text { duodeno }\end{array}$ & 39,15 & $3,50 \times 12,05$ \\
\hline Jejuno-íleo & 225,05 & 3,40 \\
\hline Ceco direito & 20,10 & 3,60 \\
\hline Ceco esquerdo & 17,40 & 4,50 \\
\hline Coloreto & 27,85 & 6,15 \\
\hline
\end{tabular}

* Comprimento X Largura X Espessura

Quadro 3: Comprimento e diâmetro dos componentes do tubo digestivo de um exemplar seriema, no 2

\begin{tabular}{|l|c|c|}
\hline \multicolumn{1}{|c|}{ Órgão } & Comprimento (mm) & Diâmetro (mm) \\
\hline Esôfago cervical & 195,90 & 12,05 \\
\hline Esôfago torácico & 81,90 & 20,00 \\
\hline Proventrículo & 46,70 & 26,80 \\
\hline $\begin{array}{l}\text { Ventrículo } * \\
\text { Alça descendente do } \\
\text { duodeno }\end{array}$ & 104,05 & 10,80 \\
\hline $\begin{array}{l}\text { Alça ascendente do } \\
\text { duodeno }\end{array}$ & 84,90 & 14,05 \\
\hline Jejuno-íleo & 562,65 & 15,05 \\
\hline Ceco direito & 229,30 & 17,10 \\
\hline Ceco esquerdo & 247,05 & 15,60 \\
\hline Coloreto & 91,10 & 15,70 \\
\hline
\end{tabular}

\footnotetext{
* Comprimento X Largura X Espessura
} 
Quadro 4: Comprimento e diâmetro dos componentes do tubo digestivo de um exemplar saracuraçu, no 3

\begin{tabular}{|l|c|c|}
\hline \multicolumn{1}{|c|}{ Órgão } & Comprimento (mm) & Diâmetro (mm) \\
\hline Esôfago cervical & 94,15 & 5,40 \\
\hline Esôfago torácico & 56,55 & 6,00 \\
\hline Proventrículo & 38,55 & 10,20 \\
\hline $\begin{array}{l}\text { Ventrículo * } \\
\text { Alça descendente do } \\
\text { duodeno }\end{array}$ & 61,70 & 8,80 \\
\hline $\begin{array}{l}\text { Alça ascendente do } \\
\text { duodeno }\end{array}$ & 62,45 & $6,60 \times 19,25$ \\
\hline Jejuno-íleo & 401,60 & 5,05 \\
\hline Ceco direito & 47,70 & 4,95 \\
\hline Ceco esquerdo & 44,50 & 6,00 \\
\hline Coloreto & 91,45 & 8,20 \\
\hline
\end{tabular}

- Comprimento X Largura X Espessura

Quadro 5: Comprimento e diâmetro dos componentes do tubo digestivo de um exemplar frango-d' água-azul, no 4

\begin{tabular}{|l|c|c|}
\hline \multicolumn{1}{|c|}{ Órgão } & Comprimento (mm) & Diâmetro (mm) \\
\hline Esôfago cervical & 65,95 & 10,35 \\
\hline Esôfago torácico & 33,45 & 7,20 \\
\hline Proventrículo & 21,45 & 6,05 \\
\hline $\begin{array}{l}\text { Ventrículo * } \\
\text { Alça descendente do } \\
\text { duodeno }\end{array}$ & 35,40 & 4,45 \\
\hline $\begin{array}{l}\text { Alça ascendente do } \\
\text { duodeno }\end{array}$ & $39,85 \times 13,15$ \\
\hline Jejuno-íleo & 182,70 & 4,70 \\
\hline Ceco direito & 17,85 & 4,15 \\
\hline Ceco esquerdo & 18,20 & 4,30 \\
\hline Coloreto & 31,40 & 4,05 \\
\hline
\end{tabular}


Quadro 6: Comprimento e diâmetro dos componentes do tubo digestivo de frango-d' água-azul, no 4.1

\begin{tabular}{|l|c|c|}
\hline \multicolumn{1}{|c|}{ Órgão } & Comprimento (mm) & Diâmetro (mm) \\
\hline Esôfago cervical & 74,10 & 5,20 \\
\hline Esôfago torácico & 34,30 & 2,50 \\
\hline Proventrículo & 23,50 & 5,25 \\
\hline $\begin{array}{l}\text { Ventrículo * } \\
\text { Alça descendente do } \\
\text { duodeno }\end{array}$ & 35,60 & 3,20 \\
\hline $\begin{array}{l}\text { Alça ascendente do } \\
\text { duodeno }\end{array}$ & 39,55 & 3,60 \\
\hline Jejuno-íleo & 198,95 & 3,10 \\
\hline Ceco direito & 20,20 & 5,70 \\
\hline Ceco esquerdo & 22,25 & 8,05 \\
\hline Coloreto & 39,65 & 7,85 \\
\hline
\end{tabular}

* Comprimento X Largura X Espessura

\section{DISCUSSÃo}

Segundo Duke (1996) o volume e o comprimento do trato digestório variam consideravelmente entre as espécies dependendo, sobretudo dos hábitos alimentares. Como foi vivenciado pelos autores Nickel, Schummer e Seiferle (1977) a porção cervical do esôfago é mais longa que a torácica, característica anatômica observada em todas as espécies estudadas.

Concordando com Dyce, Sack e Wensing (1997) a porção cervical tem início na face ventral do pescoço e logo no terço inicial desvia-se para o lado direito mantendo-se dorsalmente ou dorsolateralmente à traqueia.

Em nenhuma das espécies estudadas o esôfago cervical segue pela linha média do pescoço desviando-se caudalmente para o lado direito, como relatou Nickel, Schummer e Seiferle (1977) e Getty (1986) e nem posicionado ventralmente à traqueia (GETTY, 1986).

O estômago é dividido em proventrículo e ventrículo (NICKEL, SCHUMMER e SEIFERLE, 1977; MACARI, FURLAN e NAKAGHI, 1994; BENNETT 
SANTOS, A.L.Q. et al. Estudo morfológico comparado do trato gastrointestinal de gruiformes. PUBVET, Londrina, V. 6, N. 13, Ed. 200, Art. 1342, 2012.

e DEEM, 1996) os quais são anatomicamente e fisiologicamente distintos (NICKEL, SCHUMMER e SEIFERLE, 1977). Essas características foram observadas em todas as espécies.

O proventrículo é pequeno e situa-se cranialmente ao grande ventrículo, separado do mesmo por uma distinta constricção, o istmo, como descreveu Getty (1986). Observou-se uma relação do proventrículo com a face ventral do lobo hepático esquerdo em todas as espécies, concordando com o citado por esse autor.

Houve uma significativa variação de comprimento intestinal entre as espécies bem como diferenças em posição e forma, sugerindo uma relação direta com o tipo de alimentação, conforme afirmam Macari, Furlan e Nakaghi (1994). Concordando com o fato de que valores relativos ao comprimento variam consideravelmente mesmo de espécie para espécie (NICKEL, SCHUMMER e SEIFERLE, 1977) considerou-se dimensões médias do segmento (em porcentagem) em relação ao comprimento total do(s) representante(s).

O duodeno é o segmento mais ventral do intestino (DEEM e BENNETT, 1996). Segundo este autor, se estende da porção cranial da face lateral direita do ventrículo. Nos Gruiformes emerge da face dorsal do ventrículo. A medida de comprimento e diâmetro obtida dos exemplares de frango-d 'água-azul assemelham-se aos citados por Andrade et al. (2004), Souza et al. (2005) e Borges et al.(2004) .

Em todas as espécies, a união da porção descendente com a porção ascendente do duodeno ocorre em nível do terço final do coloreto, ventralmente a este, conforme já descrito por Getty (1986).

Segundo Getty (1986) a maior parte da porção ascendente situa-se próximo ao jejuno, à direita, e ao íleo e ceco esquerdo, dorsalmente, discordando do observado nas aves estudadas da ordem Gruiformes. Em todas as espécies relacionou-se à superfície dorsal do fígado, testículo direito ou ovário, de acordo com a citação de Nickel, Schummer e Seiferle (1977). 
SANTOS, A.L.Q. et al. Estudo morfológico comparado do trato gastrointestinal de gruiformes. PUBVET, Londrina, V. 6, N. 13, Ed. 200, Art. 1342, 2012.

Esse segmento apresenta medidas de comprimento e diâmetro próximos aos valores citados por Andrade et al. (2004) Borges e et al. (2004) e Souza et al. (2005) para frango-d 'água-azul.

Nickel, Schummer e Seiferle (1977) relatam que a união entre o duodeno e jejuno-íleo ocorre em nível do lobo renal cranial direito, igualmente ao observado em todas as espécies.

O intestino delgado é dividido em três segmentos distintos, denominados duodeno, jejuno e íleo por Deem e Bennett (1996) Dyce, Sack e Wensing (1997) Getty (1986) Nickel, Schummer e Seiferle (1977) Andrade et al. (2004) e Borges et al. (2004). Ao contrário, este estudo considera apenas dois segmentos distintos denominados duodeno e jejuno-íleo, assim como Souza et al. (2005).

O segmento jejunoilíaco forma alças dispostas em " $U$ " em todas as espécies, concordando com Deem e Bennett (1996). Estão disposta uma sobre a outra, predominantemente no antímero direito da cavidade, como cita Dyce, Sack e Wensing (1997).

Vivenciou-se que em todas as espécies o intestino grosso compreende um par de cecos e o cólon, como relata Nickel, Schummer e Seiferle (1977) e Dyce, Sack e Wensing (1997).

São realmente muito curtos em aves passeriformes e pombos, como cita Dyce, Sack e Wensing (1997) e localizam-se na junção dos intestinos delgado e grosso (DUKE, 1996) em todas as aves nas quais estão presentes. Possuem medidas de comprimento e diâmetro próximos aos obtidos por Borges et al. (2004) para frango-d' água-azul e por Santos, Leme e Kanayma (1996).

Coloreto foi o termo utilizado para denominar o último segmento intestinal, diferindo de Nickel, Schummer e Seiferle (1977) que utiliza "cólon" e Getty (1986) e Schwarze (1980) que optaram por "reto". Estende-se da união ileocecal à cloaca, nas aves providas de ceco, assim como relata Deem e Bennett (1996) localiza-se na parte dorsal do quadrante caudal esquerdo da cavidade celômica, como cita este mesmo autor. 
SANTOS, A.L.Q. et al. Estudo morfológico comparado do trato gastrointestinal de gruiformes. PUBVET, Londrina, V. 6, N. 13, Ed. 200, Art. 1342, 2012.

Em frango-d' água-azul possui dimensões próximas às obtidas nos estudos de Andrade et al. (2004), Souza et al. (2005) e Borges et al. (2004).

\section{CONCLUSÕES}

O tubo digestório apresenta poucas variações topográficas entre as espécies da ordem Gruiformes estudadas. Observou-se que a porção cervical representa o maior comprimento total do trato gastrointestinal das aves.

Notificou-se formato fusiforme característico no estomago químico em frango-d' água-azul, quando comparado com as outras espécies.

O conhecimento de particularidades anatômicas do tubo digestório das diferentes espécies é imprescindível na interpretação correta e completa das imagens radiográficas de uma ave, bem como na execução de procedimentos de rotina e intervenções cirúrgicas.

\section{REFERÊNCIAS}

ANDRADE, M. B.; SANTOS, A. L. Q.; CARVALHO, S. F. M.; BORGES, K. M.; OlEGÁRIO, M. M. M.; DIAS, E. A.; PEREIRA, R. V. V.; PEREIRA, P. C.; MIRANDA, R. L.; SILVA, C. B.; CASTRO, J. B.; ANDRADE, T. D.; COLICHINI, P. A. Descrição anatômica do tudo digestivo de Agapornispersonatafischeri (PSITTACIDAE). In: ENCONTRO DE CIÊNCIAS AVÍCOLAS, 7., 2004, Uberlândia. Anais... Uberlândia: UFU. 2004, p. 13.

BENNETT AVERY, R.; DEEM, S. L. O sistema gastrointestinal das aves: I. Compêndio de Educação Continuada - para o Médico Veterinário, Florida, v. 1, n. 1, p. 50-56, 1996.

BORGES, K. M.; ANDRADE, M. B.; OLEGÁRIO, M. M. M.; SILVA, C. B.; CASTRO, J. B.; CARVALHO, S. F. M.; SANTOS, A. L. Q. Descrição anatômica do tubo digestivo de frango-d' água-azul (Porphyrulamartinica - LINNAEUS, 1776). In: SEMANA ACADÊMICA DA UNIVERSIDADE FEDERAL DE UBERLÂNDIA, 1., 2004, Uberlândia. Anais... Uberlândia: UFU, 2004. 1CD-Rom.

Cook, R.H. e Bird, F.H. Duodenal villus area and epithelial cellular migration in convention and germ-free chicks. Poultry Science, 1973. 52, p. 2276-2280.

DUKE, G. E. Digestão nas aves. In: DUKES, H. H. Duke/Fisiologia dos animais domésticos. 11 ed. Rio de Janeiro: Guanabara Koogan, 1996. p. 390-397.

DYCE, K. M.; SACK, W. O.; WENSING, C. J. G. Tratado de anatomia veterinária. 2 ed. Rio de Janeiro: Guanabara Koogan, 1997. P.663. 
FRANZO, V.S.; ARTONI, S.M.B.; VULCANI, V.A.S.; AMOROSO, L.; OLIVEIRA, D. Biometria do intestino de poedeiras comerciais submetidas a diferentes programas de muda forçada. Ciência Animal Brasileira, Jaboticabal, n2. p. 874-882, 15 out. 2008.

GETTY. Robert. Sesson, Grossman Anatomia dos animais domésticos. 5. Ed. Rio de Janeiro: Guanabara Koogan, 1986. 1134 p. v.1.

NICKEL, R.; SCHUMMER, A; SEIFERLE, E. Anatomy of the domestic birds. Berlin: Verlag Paul Parey. p. 95-97. 1977.

NICOLAU, A. A. et al. O sevofluorano em psitacídeos (Amazona aestiva). Determinação da dose mínima (D.A.M) para produção de anestesia geral. Ciência Rural, Santa Maria, v. 32, n. 5, set/out. 2002.

MACARI, M.; FURLAN, R.L.; NAKAGHI, L.O. Anatomia e Histologia Funcional do Trato Digestivo. In: MENDES, Ariel Antonio; GONZALES, Elisabeth. Fisiologia da Digestão e Absorção das Aves. Jaboticabal: Facta, 1994. p. 01-18.

MCLELLAND, J. Sistema digestivo das aves. In: GETTY, R. Sisson/Grossman: Anatomia dos animais domésticos. $5^{\circ}$ ed. Rio de Janeiro: Guanabara Koogan, 1986. p. 1445-1464.

PELICANO, E.R.L.; SOUZA, P.A.; SOUZA, H.B.A.; OBA, A.; NORKUS, E.A.; KODAWARA, L.M.; LIMA, T.M.A. Morfometria e Ultraestrutura da Mucosa Intestinal de Frangos de Corte alimentados com Dietas contendo diferentes Pro bióticos. Revista Portuguesa de Ciências Veterinárias, Jaboticabal, p.125-134, 2003.

POUGH, F. H.; HEISER, J. B.; MCFARLAND, W. N. Características das aves: especializações para o vôo. In: A vida dos vertebrados. 2 ed. São Paulo: Atheneu, 1999. cap. 17, p. 521552.

RENCTAS (2002) 10 relatório nacional sobre o tráfico de fauna silvestre. Brasília: Rede Nacional de Combate ao Tráfico de Animais Silvestres (RENCTAS).

SANTOS, A. L. Q.; LEME, M. C.; KANAYAMA, C. Y. Anatomia do intestino do Spheniscusmagelanicus (Pingüim-de-magalhães). In: CONGRESSO PANAMERICANO DE CIÊNCIAS VETERINÁRIAS, 16.,1996, Campo Grande. Anais... Campo Grande: CBC, 1996. PN2.942.

SOUZA, A. G.; BORGES, K. M.; OlEGÁRIO, M. M. M.; ANDRADE, M. B.; PEREIRA, P. C.; SANTOS, A. L. Q.; VIEIRA, L. G. Descrição anatômica do tudo digestivo de periquitoaustraliano-azul (Melopsittacusundulatus). (FRINGILLIDAE). In: ENCONTRO SOBRE ANIMAIS SELVAGENS - MANEJO E CONSERVAÇÃO, 3., 2005, Uberlândia. Resumos... Uberlândia: Universidade Federal de Uberlândia, 2005.

SCHWARZE, E. Compêndio de anatomia veterinária - anatomia de aves. Zaragoza: Acribia, 1980. 212 p. 